\title{
Practice on Innovation and entrepreneurship talent development of Automotive Professional Students
}

\author{
Danni Song ${ }^{\mathrm{a}}$, Rong Zeng ${ }^{\mathrm{b}^{\star}}$ \\ Wuhan University of Technology Huaxia College, Wuhan 430000, China. \\ anier @163.com, ${ }^{\mathrm{b}}$ zeng@126.com \\ ${ }^{\star}$ Corresponding author
}

Keywords: Automotive Professional, innovation and entrepreneurship, talent development.

\begin{abstract}
China will enter an innovative country by 2020, building an innovative country, largely depends on innovation and entrepreneurship, the scale and quality, and innovation and entrepreneurship culture is largely dependent on innovation and entrepreneurship and Universities education. Based on this background, the paper study the students of automotive professional, analyze the status quo automotive innovation and entrepreneurship talent development, proposed automobile innovation and entrepreneurship culture should start from a personnel training program, the construction of campus practice teaching base, strengthen "double" teaching team building, innovation and entrepreneurship to build campus platform to drive innovation and entrepreneurship projects.
\end{abstract}

\section{Introduction}

With the reform and development of higher education, to solve the employment problem of students, colleges and universities need to radically change their ideas, change the traditional training model of talent, market-oriented, innovative entrepreneurship education. However, although many colleges and universities in vigorously promoting publicity and guide innovation and entrepreneurship education, innovation and entrepreneurial heritage but because not enough teachers is not strong, the lack of innovation and entrepreneurship education environment and platform, resulting in very little innovation and entrepreneurship education outcomes. Therefore, building and implementation of innovative talents training system Students at the university desperately needed. In this paper, Wuhan University of Technology Huaxia College automobile majors as an object of innovation and entrepreneurship, auto connotation to define, analyze the status quo Automotive innovation and entrepreneurship talent development, and propose ways Automotive innovation and entrepreneurship talent development.

\section{Analysis Situation of innovation and entrepreneurship of Automotive}

Automotive innovation and entrepreneurship Definition. Cars talent refers not only to automobile manufacturing-related aspects of personnel, should also cover automobile manufacturing, car service, motor sport, car Expo and other related personnel. In the present study that the car innovation and entrepreneurship should cover the automobile industry chain, with automotive marketing, law, international trade and other related theories and basic auto repair, car sales and vehicle detection and diagnosis and evaluation basis, understand automotive R \& D and Design Technology, good service, and can engage in auto-related management of compound talents. 
Culture characteristics of automotive innovation and entrepreneurship. The objective of Automotive Professional talent development is to focus on rapid development of China's auto industry and adapted to regional economic development and social needs, combined with reform of higher education, closely linked "Internet +" era background, school internship training base as the basis, competency-campus training base, innovation and entrepreneurship education for the purpose of combining theory and practice, students' "skilled, service, performance management”, with innovative and pioneering spirit of compound talents.

Situation Analysis of Innovation and Entrepreneurship talent development of Automotive Professional. With the deepening reform of higher education, innovation and entrepreneurship education philosophy gradually pay attention to institutions of higher learning in the school also launched a variety of "innovation and entrepreneurship" trend, mainly in the "technological innovation" category competition, innovation base in schools and other forms of conduct as the basis expand, but because research teachers, capital investment, innovation and entrepreneurship heritage shortage and other reasons, although the "innovation and entrepreneurship" in the implementation, but the effect is not obvious.

(1)Relatively simple of Talent level. Currently, most colleges trained people focused on automotive $R \& D$, sales and service cars, auto insurance and claims, used car assessment and evaluation, maintenance, etc., and the need to foster innovation and entrepreneurship education on the one hand the common people, to engage transnational management, vehicle design, vehicle development, powertrain design and development, key components, prototype testing, brand management, marketing, supply chain management, program management, project management, financial management, etc; the other side needs to market guide, develop new energy-specific talent; at the same time students can engage in car culture and other related work.

(2)Innovation capability is weak. Cars Students need to be multi-disciplinary theoretical knowledge, such as machinery, materials, electrical and other management, greater student curriculum, course content than the norm. But students get on technological Innovation, they need to cross-disciplinary or multi-disciplinary integration, and the need to focus on the ability of some main subjects outside, such as computer programming, software design. While many professional disciplines have begun to focus on integration, sub-direction additional elective courses, but the main emphasis on theory, short hours, low ratio of practice. Students carrying out scientific and technological innovation projects, mainly through the division of the team, to overcome through self-innovation capability needs, many of the projects can not meet the needs of scientific and technological innovation capacity and give up halfway due to the ability of students.

(3)Entrepreneurship concept is not deep. According to my school Graduate Employment Survey, 2015, a total of 324 cars graduates, including 234 undergraduate, 90 specialist, 296 jobs have been verified, accounting for $91.36 \%$; 30 postgraduate admissions, accounting for $12.82 \%$. Graduates focused on design firms, OEMs, car insurance companies, car sales companies, car companies and other integrated services, the other for cross-professional jobs, mainly in the post survey to assess the damage, automobile design, automobile factory production, auto $4 \mathrm{~S}$ store sales, vehicle maintenance and automotive beauty (Figure 1). Less number of students start their own businesses, only one person in the creation of a car repair shop, there are a few people in the shop, dance studios. Students mainly follow traditional concepts after graduation to find a job or studies, lack of entrepreneurial awareness in student life. In his school life, school instill entrepreneurial concept is not strong, the lack of entrepreneurial case to guide students. 


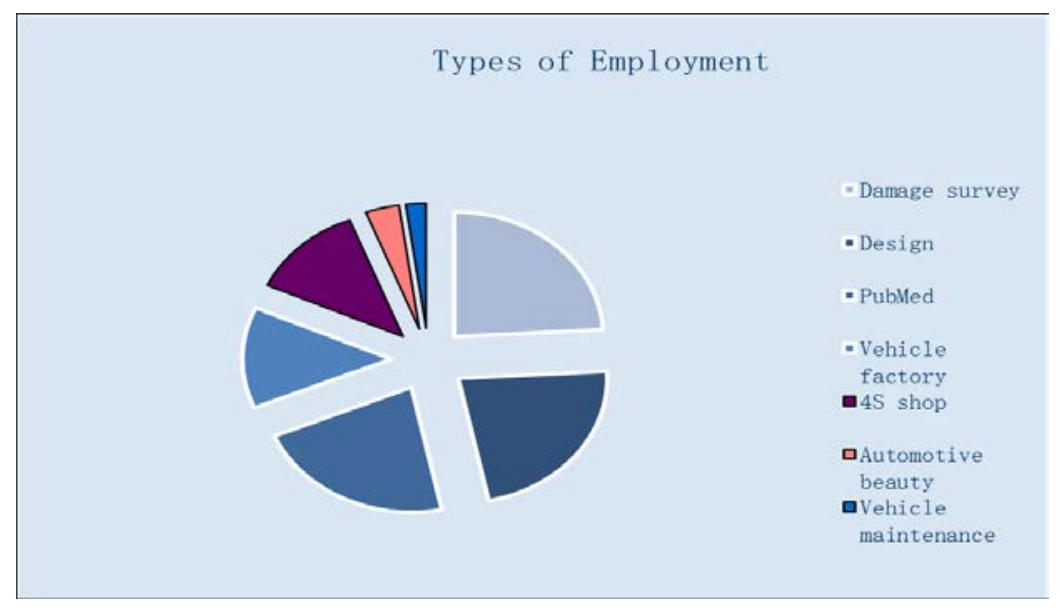

Fig. 1 Distribution of Employment Type

\section{Path analysis of innovation and entrepreneurship talent development of Automotive}

Developing new talent development plan. Training creative talents must be the appropriate course or additional links in personnel training program, but also to increase its proportion. Automotive professional training school open plan "entrepreneurship education" courses to train students 'innovation and entrepreneurship' concept, while additional expand the quality and innovation and entrepreneurship module (Table 1), and a corresponding credit requirements, which prompted students to actively to carry out scientific and technological innovation, entrepreneurship, and establish the concept of innovation and entrepreneurship, innovation and entrepreneurship to improve.

Table 1 The module of quality development and innovation entrepreneurship

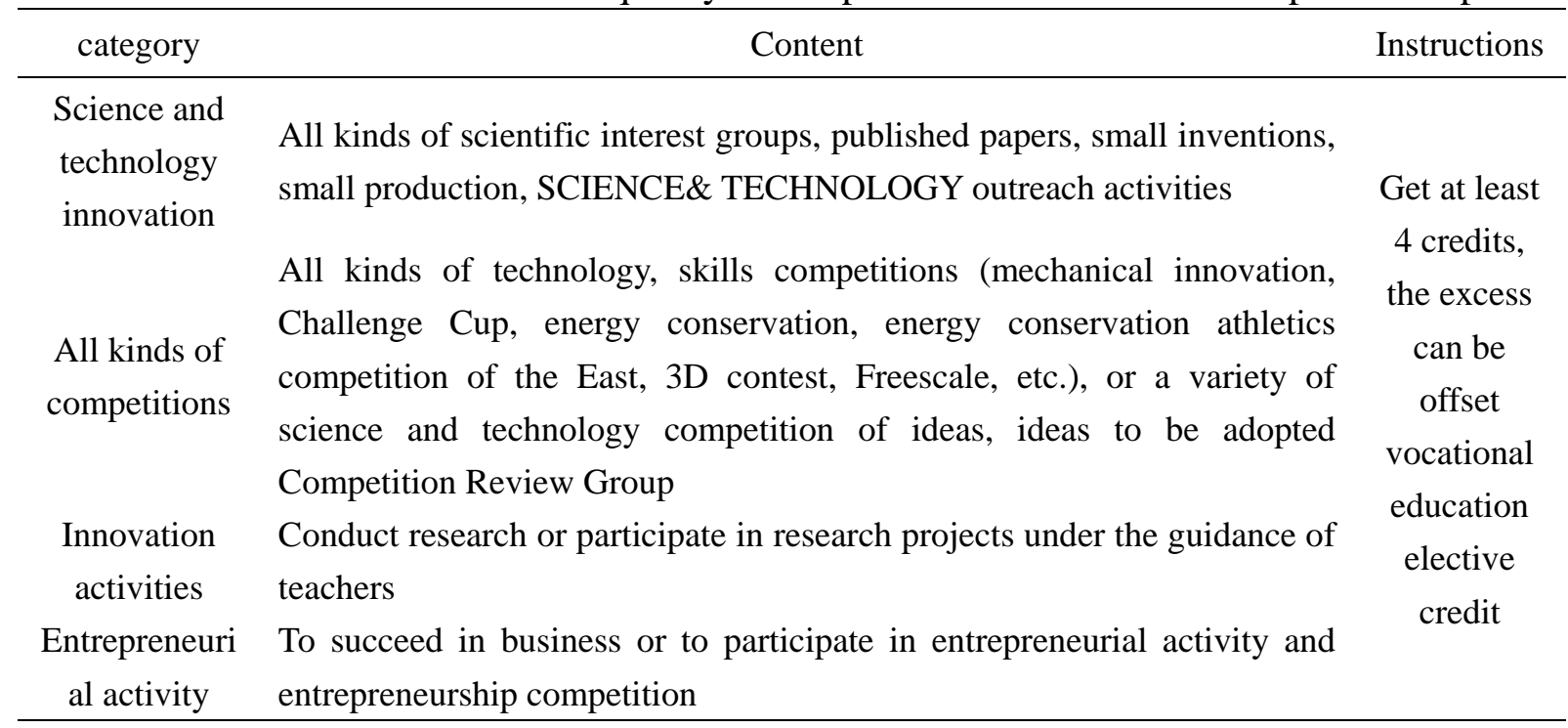

Building the base of Practice teaching out of schools. Automotive Specialty has a certain particularity, schools have cars of various types of laboratory or campus training base, students practical ability, but basically the market demand-oriented, to develop students ability to adapt to jobs, the practice hands-on capacity than a single. The students should be innovation and entrepreneurship, it must have a strong practical ability, then it must be established off-campus practice teaching base, innovation and entrepreneurship to enable students to diversify. At the same time, it allows students in school practice, seek ideas and methods of innovation and entrepreneurship.

Strengthening "double type" teaching team building. Our innovation and entrepreneurship education started late, the current innovation and entrepreneurship education most colleges and 
universities is still in the "concept" stage of cultivation, while innovation and entrepreneurship education involves discipline integration, strong technical and practical, innovation and entrepreneurship Most teachers stay in the theoretical level the lack of a high level of innovation, the lack of practical business management and venture capital efforts, teachers can not meet the overall demand for innovative entrepreneurship education. Then we need schools to develop appropriate incentives to strengthen the "Double" Teachers encourage teachers out of school, in-depth business practices to enhance understanding of the frontier, training teachers creative and practical ability, or the introduction of senior corporate personnel, student innovation and entrepreneurship guidance, innovation and entrepreneurship to achieve efficient outcomes.

Building the platform of innovation and entrepreneurship in schools, using innovation and entrepreneurship project as the driving. Automobile Majors with particular emphasis on practical application-oriented professionals, through a variety of ways for students to build a platform for innovation and entrepreneurship, innovation and entrepreneurship to carry out projects. When setting up a platform for innovation and entrepreneurship, innovation-driven venture, teachers guide students.

Innovation and entrepreneurship projects can be organized students to participate in various university student innovation and entrepreneurship competition, such as the "Challenge Cup", "mechanical innovation competition", etc., to provide specialized classroom or school grounds, purchase the appropriate equipment, the establishment of appropriate rules and regulations to old and new, with a low-grade to high-grade, next term heritage, to create a good atmosphere. May also be specific business projects, given the appropriate school site or financial support, auto physical stores opened. Automotive professional characteristics, can be combined with practical training base automobile vehicle maintenance beauty shop opened, providing simple car maintenance, repair and other services, and ultimately build a virtual set of exercises and actual combat experience in one of the practical platform for innovation and entrepreneurship, science, comprehensive and systematic innovation and entrepreneurship students practical ability.

\section{Summary}

For very practical automotive professionals, in order to improve the car Undergraduate students' innovative entrepreneurship must be targeted through practice and training, it can be effectively improved. So first of all to instill the concept of innovation and entrepreneurship, innovation and entrepreneurship platform to build schools, to create a favorable climate for innovation and entrepreneurship, the majority of students, innovation and entrepreneurship to generate interest. The second is to focus on innovation and entrepreneurship teachers, cultivating "Double Teachers" team, which is automobile undergraduates innovation and entrepreneurship capacity increased assurance. In addition to strengthening innovation and entrepreneurship Practice Teaching Base Construction and cultivate practical ability. Finally, in order to drive innovation and entrepreneurship projects, giving students the opportunity to participate in all kinds of innovation and entrepreneurship practice, through the design and implementation of innovative entrepreneurial projects rapidly improve students' innovative entrepreneurship.

\section{Acknowledgements}

Teaching research project of Wuhan University of Technology Huaxia college (Research on the training mode and practice of innovation and entrepreneurial talents of automobile based on Transformation 1503). Teaching research project of Wuhan University of Technology Huaxia 
college (Cars professional and technical skilled personnel training curriculum system $\backslash$ teaching content and Practice in Construction 1403)

\section{References}

[1] Junhuan Meng: Personnel training and personnel needs of the automotive industry to adapt to countermeasures. China Adult Education,(2015),p.356-357.

[2] Degang Lv,Xianyue Zhang: Automotive Undergraduate Innovation and Entrepreneurship Capacity Building Modellearned journal of Qinzhou College, (2014)No.11,p234-235. 